\title{
Energy and Carbon Modeling with Multi-Criteria Decision-Making towards Sustainable Industrial Sector Development in Thailand
}

\author{
Aumnad Phdungsilp, Teeradej Wuttipornpun \\ Department of Industrial Engineering, King Mongkut’s University of Technology North Bangkok, Bangkok, Thailand. \\ Email:aumnad@gmail.com
}

Received July 11 ${ }^{\text {th }}$, 2011; revised August $4^{\text {th }}, 2011$; accepted August $10^{\text {th }}, 2011$.

\begin{abstract}
This paper develops some policy options for Thailand's industrial sector. The energy simulation model, the Long-range Energy Alternatives Planning (LEAP) system, has been used to simulate how energy might develop from 2005-2030. Five policy interventions are selected, and how these would change energy development is examined, and compared to a reference case. Further, the industrial policy options are assessed using a multi-criteria decision-making framework. Results of this study can increase the knowledge and understanding to make an explicit consideration of the transition from high carbon intensive energy system to one which is substantially decarbonized. The most significant energy-savings are improvement of energy efficiency and process integration. These policy options also have the large potential to reduce $\mathrm{CO}_{2}$ emissions.
\end{abstract}

Keywords: $\mathrm{CO}_{2}$ Emissions, Energy Modeling, Industrial Sector, Multi-Criteria Decision-Making

\section{Introduction}

Climate change and energy issues are demanding new efforts to addressing the challenges. Significant changes have taken place on the world energy scene, which have important implications for energy planning. Globally, the industrial sector accounts for $40 \%$ of primary energy demand and approximately the same share for $\mathrm{CO}_{2}$ emissions. Mitigation can be substantially cut in this sector through policies, initiatives and efficient energy technologies. Thailand's industrial sector consists of manufacturing, mining and construction industries. The manufacturing industry accounts for more than $90 \%$ of total energy consumption in the industrial sector. Besides, the manufacturing industry contributes about $95 \%$ of $\mathrm{CO}_{2}$ emissions from industrial sector, while construction and mining industries contribute the rest [1]. Therefore, preparing appropriate actions can significantly reduce energy demand and associated $\mathrm{CO}_{2}$ emissions.

There are few studies of energy scenarios in Thailand, particularly in the industrial sector, make an explicit consideration of the transition from high carbon intensive energy system to one which is substantially decarbonizes. This paper is motivated by the need to help decisionmakers to prepare scientific-based policy, and to analyze industrial energy demand and associated emissions in a sustainable way. The paper would provide an in-depth understanding of the complex dynamics of energy and $\mathrm{CO}_{2}$ issues related to structure of industrial energy use patterns. In addition, it can produce a scientific knowledge to aid decision-makers in preparing with pathway towards low-carbon economy. Planning for a low-carbon society requires processes of analysis and decisionmaking about what resources and technologies to be used and pathways to achieve.

This paper aims to develop energy and carbon modeling of Thai industrial sector and some policy options. It outlines and assesses the current status and future development related to energy consumption and $\mathrm{CO}_{2}$ emissions over the twenty-five years from 2005-2030. The simulation model, the Long-range Energy Alternative Planning (LEAP) system, is used to simulate what might happen to energy demand and carbon emissions in the future in a business-as-usual (BAU) case and with alternate scenario. The BAU scenario provides a baseline vision of how energy consumption and $\mathrm{CO}_{2}$ emissions are likely to evolve, while alternate scenario explores a range of policy interventions. The study goes further in applying a decision support tool to evaluate different 
policy options based on multi-criteria decision-making (MCDM) approach. The scope of this paper is focused on only manufacturing industries, including food and beverages, textiles, wood and furniture, paper, chemical, non-metallic, basic metal, fabricated metal, and others (unclassified).

\section{Background Information of Thailand's Industrial Sector}

The industrial sector is extremely diverse and includes a wide range of activities. Thai industry has grown significantly over the past two decades. Industrial value-added has increased from 255.5 billion Thai Baht in 1981 to 1,043.2 billion Thai Baht in 2000 at constant 1988 prices. Manufacturing industry has a dominant share and its importance has increased from about $80 \%$ in 1981 to above $91 \%$ in 2000 . The growth rate of manufacturing valueadded accelerated from $5 \%$ to $15 \%$ per year between the first and second half of the 1980s, and continued to grow rapidly by $11 \%$ per year in the first half of the 1990 s. This was primarily due to the growth of manufacturing exports. As a result, manufacturing's contribution to overall gross domestic product (GDP) increased rapidly from $23 \%$ to $31 \%$ between 1980 and 1995 . This performance came to an abrupt halt in 1996, when manufacturing exports declined. In the period 1996-2000, manufacturing value-added and exports grew by an average of $3 \%$ and $2 \%$ per year.

Thai manufacturing industry has undergone some structural changes during 1981-2000. Food and beverage was among the largest contributors to the manufacturing sector value-added in the early to mid-1980s. The share of the export-oriented textile industries peaked during late 1980s. Two groups of industries have gained in shares: other industries and chemical industries. The industrial sector has begun the largest energy consuming sector in Thailand since 2005 [2]. By fuel types, oil is the largest share of total final energy consumption. The gradual substitution of fuel-oil with natural gas and the slow growth in diesel demand result in the decline in the share of oil. Natural gas is expected to grow faster rate. Thai government has policies to improve energy efficiency and the shift of the industrial structure from energy intensive to non-energy intensive industries. Within manufacturing sector, $\mathrm{CO}_{2}$ emissions from food and nonmetallic industries dominate over others. Food industry accounted for about $49 \%$ of $\mathrm{CO}_{2}$ emissions in 1981 but its share has fallen to $29 \%$ in 2000 . Shares of non-metallic industry and chemical industry in $\mathrm{CO}_{2}$ emissions have increased from about $24 \%$ and $5 \%$ in 1981 to $27.5 \%$ and $13 \%$ in 2000, respectively. Thus, food, non-metallic and chemical industries account for about $70 \%$ of $\mathrm{CO}_{2}$ emis- sions [1].

\section{Methodology}

\subsection{LEAP Model}

Energy modeling is an important part of the methodology. Various energy models are available to develop policy cases quantitatively and to provide a consistent framework of their analysis. LEAP is a simulation model for energy planning tool. It is not a model of a particular energy system, but rather a tool that can be used to create models of different energy systems. The central concept of LEAP is an end-use driven model in which users create quantitative descriptions of current and future energy demand and supply and environmental scenarios. The model includes the Technology and Environmental Database (TED), which provides extensive information on the technical characteristics and environmental impacts of energy technologies [3].

This paper looks into the development pathways of energy consumption and energy-related $\mathrm{CO}_{2}$ emissions, and the potentials of reducing energy consumption and emissions in Thai manufacturing industries. The model is disaggregated in a hierarchical tree structure of four levels: sector, sub-sector, end-use, and device. The main driver in energy consumption is the production of commodities. The disaggregation introduces physical energy intensities in terms of energy use per ton of industrial product produced for a portion of the industrial sector. The energy demand is formulated as a function of GDP, proportion of energy utilization, device efficiency, and useful energy intensity. The useful energy intensity is estimated as follows:

$$
U E I_{j}=\sum_{t} \frac{\left(E n U_{i, j} \times \eta_{i, j}\right)}{G D P_{j}}
$$

where $U E I_{j}$ represents the energy intensity in industrial sub-sector $j$ (ktoe/10 $10^{6} \mathrm{Baht}$ ), $E n U_{i, j}$ is the energy type $\mathrm{i}$ utilized in sub-sector $j$ (ktoe), $\eta_{i, j}$ is the efficiency of equipment using fuel type $i$ utilized in sub-sector $j$, and GDP is gross domestic products of industrial sub-sector $j$ (10 $0^{6}$ Baht).

\subsection{Multi-Criteria Decision-Making}

A framework of the MCDM method used in this study can be seen as two main phases. In the first phase, decision team decides on the criteria they want to use and determine their relative importance. In this paper, the selection of main criteria and sub-criteria are followed the study conducted by [4]. In the second phase, the decision group applies the MCDM method to judge the relative merits of the alternatives. This is done by deter- 
mining scores for each alternative for each criterion using the measuring scales defined in the first phase.

The application of MCDM was carried out in a laboratory setting. Five people with a background in energy, engineering, economic, environment, and political were contacted and communicated. They were asked to imagine themselves to be the decision-makers in charge of making decisions. One of the authors was assigned as the resident MCDM expert, that responsible for organizing the information and following other processes. Thus, other members do not need to become familiar with the mechanics of aggregating the information and running MCDM calculation.

The objective of the study is to propose sustainable energy system. The criteria for energy system assessment reflect three main aspects, including environmental, economic and social. Some criteria and sub-criteria are quantifiable, while others are qualitative. The performance prediction is done based on computer simulation (energy modeling), databases, rules of thumb, and experience or expert judgment. Qualitative values are words or phrases that can be used to characterize how well a scheme rates against a particular criteria. These are quality issues, such as public acceptance or integration into an urban context. The criteria weights are determined using a mathematical technique so-called Analytic Hierarchy Process (AHP). AHP enables to structure a complex problem in the form of hierarchy and to evaluate a large number of quantitative and qualitative factors in a systematic manner under multiple conflicting criteria. AHP makes use of pairwise comparisons with 9-point ratio scaling to apply weights to attributes. Computer software Web-HIPRE (Hierarchical PREference analysis on the World Wide Web) is used in this process. For more detail of Web-HIPRE see $[5,6]$ and the AHP see [7-9].

\section{Scenario Definition}

\subsection{Scenario Description}

Energy model allows the construction of policy options in a quantitative way. The implication of policy interventions can be tested. In order to demonstrate the future energy consumption and $\mathrm{CO}_{2}$ emissions, and to evaluate the benefits of energy policies, two scenarios were developed in LEAP model under different sets of policy options-a reference scenario or BAU case and an alternate policy scenario. These scenarios are primarily governed by four factors: economic growth, proportion of energy types, efficiency of energy devices, and energy intensity. The policy options and assumptions are given in Table 1.

Scenario provides a framework for exploring future energy perspectives, including various combinations of

Table 1. Policy options and assumptions for scenario generation.

\begin{tabular}{|c|c|c|}
\hline Scenario & Policy options & Assumptions \\
\hline Business as usual & & $\begin{array}{l}\text { Historical trends will continue and the GDP growth rate } 4.5 \% \text { (2005- } \\
2010 \text { ) and 5.5\% (2011-2030). }\end{array}$ \\
\hline \multirow[t]{6}{*}{ Alternate policy } & Improvement of industrial energy efficiency (IEE) & $\begin{array}{l}\text { A target of } 10 \% \text { and } 20 \% \text { increasing energy efficiency by } 2015 \text { and } \\
\text { 2030. These improvements are from compressed air, boiler and steam } \\
\text { systems, and lighting systems. }\end{array}$ \\
\hline & Switching to natural gas (ING) & $\begin{array}{l}\text { Thermal energy supplied by non-renewable resources such as diesel and } \\
\text { fuel-oil will be switched to natural gas by } 2015 \text {. }\end{array}$ \\
\hline & Combined heat and power in designate factories (ICHP) & $\begin{array}{l}\text { Combined heat and power (CHP) systems will use to produce electricity } \\
\text { in selected industries and the waste heat will use to replace heat from } \\
\text { fuel-oil fired boilers. CHP systems will replace fuel-oil by } 2015 \text { and } \\
\text { assume that electricity consumption will decrease } 10 \% \text { in each industry. }\end{array}$ \\
\hline & Efficient electricity end-use devices (IElect) & $\begin{array}{l}\text { Only electricity will be considered-availability of efficient and less } \\
\text { energy intensive pumps, compressors and motors for industrial proc- } \\
\text { esses. This policy can consider as a part of Energy Labeling Program. It } \\
\text { is assumed that increasing } 20 \% \text { of electricity efficiency by } 2010 \text {. }\end{array}$ \\
\hline & Process integration (IPI) & $\begin{array}{l}\text { Process integration will apply to food and beverages, chemical and pa- } \\
\text { per industries. It is assumed that } 20 \% \text { reduction in useful energy inten- } \\
\text { sity by } 2015 \text {. }\end{array}$ \\
\hline & Integrated policy (IIP) & $\begin{array}{l}\text { All of the above mentioned policies are considered together. This policy } \\
\text { option would give the cumulative effect of the different options, giving } \\
\text { Thai industry the lowest possible emission reductions. }\end{array}$ \\
\hline
\end{tabular}


technology options and their implications. The scenario analysis timespan covers the years 2005-2030. All scenarios start from a common base year (2005), which is named as the current account (CA) scenario in LEAP model. CA scenario describes energy demand in industrial sector based on proven historical data. Data for the CA scenario were collected from different sources as described in the following section. The CA scenario forms the base of BAU and alternate policy scenarios.

BAU scenario assumes that past trends continue in the future and no new policies for energy-savings and emission mitigation will be implemented. Energy demand is predicted as a function of time. This scenario aims to show the future through the prism of current policies and strategies. For the BAU scenario, the current patterns in the industrial structure will be maintained and the industrial sub-sectors will be the same as in CA scenario. This implies no change compared to the industrial structure in 2005.

The alternate policy scenario is inherited from BAU scenario. It is, thus, reflected sensitivities on the original scenario. This considers the cumulative impact of five industrial energy policies, including improvement of industrial energy efficiency, switching to natural gas, CHP in designate factories, efficient electricity end-use devices, and process integration. This scenario can also consider as a mitigation scenario, which means that more ambitious energy conservation and emission reduction objectives and relevant policies are adopted. The policy options form the basis for technology selection. LEAP converts the assumptions (Table 1) into quantitative way.

\subsection{Data Sources}

This study draws on a wide variety of sources. Data were obtained from various sources: statistical information, government publications of official energy data, utility statistics, journal articles, book chapters, research reports, and others. The principle sources are Ministry of Energy [2,10] and Ministry of Industry [11-12]. Sources of data used on economic [13-14], energy [2,10,15-17], and technology issue [18-21]. Data obtained from the original source were processed to meet the input requirements in LEAP model to develop a base year dataset. Growth in GDP was assumed to be the same in all scenarios. We assumed Thailand's GDP from industrial sector will maintain its growth with an annual growth rate set to be $4.5 \%$ from 2005 to 2010 . Then the growth will grow up, with an annual growth rate set to be 5.5\% from 2010 to 2030. This assumption is based on the estimation by National Economic and Social Development Board. The industrial structure will remain constant during timeframe.

\section{Results}

\subsection{Scenario Analysis Results}

\subsubsection{Business-as Usual Scenario}

The BAU scenario represents a base case without policy interventions. It is a projection of what would happen in the absence of specific energy policy and strategy. Currently, industrial sector energy consumption accounts for around $36 \%$ of total national energy consumption, and the highly energy intensive industries, such as food and beverage, non-metallic and chemical, make up over $70 \%$ of total industrial energy demand. Detail results for BAU case are shown in Table A-1. It shows that total industrial energy demand in 2005-2030 will increase by $5.53 \%$ annually, and in 2030, the energy demand is estimated to be about 3.5 times of that of the year 2005 .

Food and beverage, non-metallic and chemical industries are expected to grow rapidly in BAU scenario. Estimated renewable energy (including bagasse, biomass and wood), coal, electricity and natural gas demands in 2030 are 20,112 ktoe, 26,573 ktoe, 19,034 ktoe and 6222 ktoe, respectively. Shares of biomass, coal, electricity and natural gas in energy demand of 2030 are estimated to be $26.5 \%, 35 \%, 25 \%$ and $8.2 \%$, respectively. Among non-renewable energy, coal, electricity and natural gas are primarily responsible for the majority of final energy demand (Table A-1).

The emissions for 2030 at BAU scenario are estimated 3.7 times for $\mathrm{CO}_{2}$ compared to the base year 2005. It should be noted that emissions from biomass are not taking into account. Non-metallic and fabricated metal are responsible for majority of the emissions in 2030 . Non-metallic is responsible for emitting about $29.5 \%$, while fabricated metal emits about $17.8 \%$ of total $\mathrm{CO}_{2}$ from industrial sector. $\mathrm{CO}_{2}$ emissions are estimated to be $68 \mathrm{MtCO}_{2}, 116 \mathrm{MtCO}_{2}$ and $198 \mathrm{MtCO}_{2}$ in 2010, 2020 and 2030, respectively. The estimations for the intermediate years are illustrated in Figure 1. Electricity and coal products are responsible for the majority of emissions.

\subsubsection{Alternate Scenario}

The alternative policy options are compared to the BAU case in order to assess their potentials of energy demand and $\mathrm{CO}_{2}$ emission reductions. Indicators are selected to compare the results from the viewpoint of avoided energy demand and avoided $\mathrm{CO}_{2}$ emissions compared to BAU case. The reduction in final energy demand in the industrial sector that occurs as a result of different policy options are shown in Table 2.

It is found that energy efficiency improvement alone would reduce energy demand by $40 \%$ from the BAU 


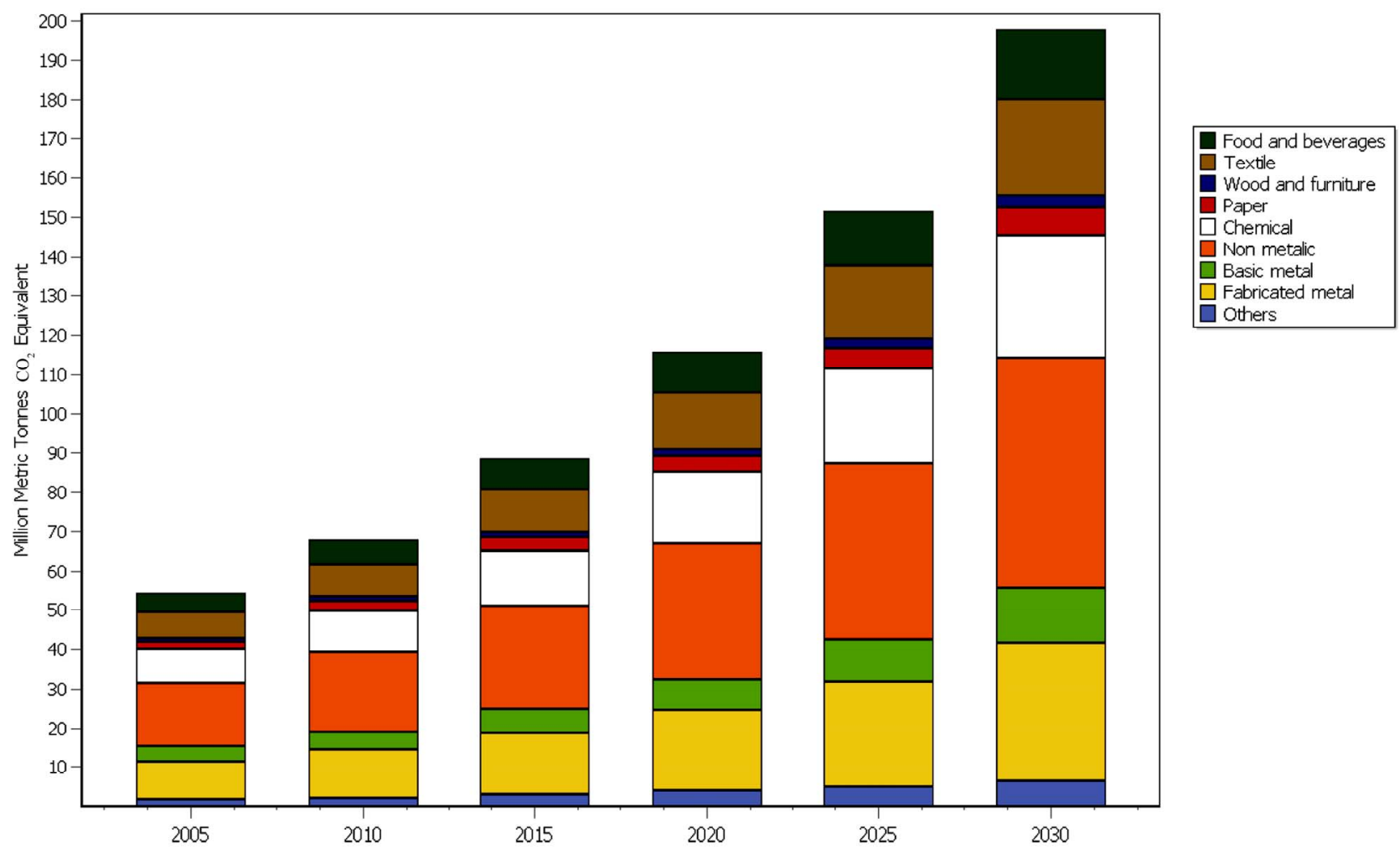

Figure 1. Estimated $\mathrm{CO}_{2}$ emissions from industrial energy consumption in BAU case.

Table 2. Avoided energy demand compared to BAU under various policies (ktoe).

\begin{tabular}{cccccc}
\hline & 2010 & 2015 & 2020 & 2025 & 2030 \\
\hline Energy efficiency improvement & 1293 & 3379 & 5904 & 9661 & 15,168 \\
Switching to natural gas & 239 & 624 & 816 & 1066 & 1393 \\
CHP in designate factories & 505 & 1321 & 1725 & 2253 & 2943 \\
Efficient electricity end-use & 1087 & 1421 & 1857 & 2427 & 3172 \\
Process integration & 2599 & 6794 & 8880 & 11,606 & 15,168 \\
Integrated policy & 5723 & 13,539 & 19,182 & 27,013 & 37,844 \\
\hline
\end{tabular}

case in 2030. The reductions of energy demand in this policy case are higher compared to the other measures, such as switching to natural gas, CHP in designate factories, and efficient electricity end-use devices. Process integration policy shows high possibility to reduce energy demand during 2010-2015. It is, however, due to the assumption in the model the potential reduction of energy demand decrease to $40 \%$ by 2030 . Implementing all of the policy options is estimated to reduce energy demand by 22\% in 2010, 43\% in 2020, and 50\% in 2030 . Such reductions would have potentials to reduce a large amount of government revenues to be spent on imported energy. The potential $\mathrm{CO}_{2}$ emission reductions in various policies are presented in Table 3.
Table 3. Reduction of $\mathrm{CO}_{2}$ emissions in various policies from BAU case $\left(\mathrm{MtCO}_{2}\right)$.

\begin{tabular}{cccccc}
\hline & 2010 & 2015 & 2020 & 2025 & 2030 \\
\hline Energy efficiency improvement & 3.37 & 8.82 & 15.39 & 25.18 & 39.51 \\
Switching to natural gas & 0.95 & 2.49 & 3.25 & 4.25 & 5.56 \\
CHP in designate factories & 2.11 & 5.52 & 7.22 & 9.43 & 12.33 \\
Efficient electricity end-use & 7.21 & 9.42 & 12.31 & 16.09 & 21.03 \\
Process integration & 6.77 & 17.7 & 23.13 & 30.23 & 39.51 \\
Integrated policy & 20.41 & 43.95 & 61.3 & 85.18 & 117.94 \\
\hline
\end{tabular}

\subsection{Evaluation of Policy Options}

There are five main criteria for this analysis, including resource use, environmental loading, financial and economic, social, and practical. Main findings are found that resource use and environmental loading equal importance on both criteria. It is also found that few differences between social and practical aspects. Among subcriteria (see Table 4).

The annual fuel is considered to be the most important of the resource use criteria. The annual $\mathrm{CO}_{2}$ emissions are evaluated as the most important and the annual $\mathrm{SO}_{2}$ emissions is more importance than annual $\mathrm{NO}_{\mathrm{x}}$ emissions in the environmental loading criteria. The market maturity is found the least important of the four aspects of the 
Table 4. Evaluation results of policy options.

\begin{tabular}{|c|c|c|c|c|c|}
\hline $\begin{array}{c}\text { Main criteria \& } \\
\text { Sub-criteria }\end{array}$ & Alt1 & Alt2 & Alt3 & Alt4 & Alt5 \\
\hline \multicolumn{6}{|l|}{ 1.Resource use } \\
\hline - Resource depletion & 0.014 & 0.003 & 0.005 & 0.006 & 0.008 \\
\hline - Annual electricity & 0.037 & 0.007 & 0.010 & 0.030 & 0.018 \\
\hline - Annual fuel & 0.083 & 0.012 & 0.019 & 0.041 & 0.038 \\
\hline \multicolumn{6}{|l|}{ 2. Enviromental } \\
\hline \multicolumn{6}{|l|}{ loading } \\
\hline $\begin{array}{c}\text { - Annual } \mathrm{CO}_{2} \\
\text { emissions }\end{array}$ & 0.084 & 0.013 & 0.023 & 0.045 & 0.084 \\
\hline $\begin{array}{c}\text { - Annual } \mathrm{SO}_{2} \\
\text { emissions }\end{array}$ & 0.012 & 0.004 & 0.005 & 0.011 & 0.023 \\
\hline $\begin{array}{c}\text { - Annual } \mathrm{NO}_{\mathrm{x}} \\
\text { emissions }\end{array}$ & 0.012 & 0.002 & 0.002 & 0.006 & 0.006 \\
\hline \multicolumn{6}{|l|}{$\begin{array}{l}\text { 3. Financial \& } \\
\text { economic }\end{array}$} \\
\hline - Construction cost & 0.009 & 0.001 & 0.002 & 0.004 & 0.004 \\
\hline $\begin{array}{c}\text { - Annual operating } \\
\text { cost }\end{array}$ & 0.023 & 0.004 & 0.005 & 0.023 & 0.010 \\
\hline $\begin{array}{c}\text { - Annual } \\
\text { maintenance }\end{array}$ & 0.010 & 0.004 & 0.003 & 0.009 & 0.012 \\
\hline $\begin{array}{c}\text { - Market maturity } \\
\text { 4. Social }\end{array}$ & \multicolumn{4}{|c|}{ 4. Social } & 0.001 \\
\hline - Job creation & 0.002 & 0.006 & 0.004 & 0.002 & 0.002 \\
\hline - Public acceptance & 0.015 & 0.003 & 0.004 & 0.012 & 0.012 \\
\hline $\begin{array}{c}\text { - Human health } \\
\text { impacts }\end{array}$ & 0.013 & 0.002 & 0.001 & 0.006 & 0.008 \\
\hline $\begin{array}{l}\text { - Integration in urban } \\
\text { context }\end{array}$ & 0.003 & 0.000 & 0.001 & 0.003 & 0.001 \\
\hline \multicolumn{6}{|l|}{ 5. Practical } \\
\hline $\begin{array}{c}\text { - Political support } \\
\text { exist }\end{array}$ & 0.008 & 0.009 & 0.007 & 0.005 & 0.002 \\
\hline - Data available & 0.003 & 0.001 & 0.001 & 0.003 & 0.000 \\
\hline - Maintainability & 0.026 & 0.005 & 0.012 & 0.027 & 0.003 \\
\hline Overall & 0.355 & 0.075 & 0.105 & 0.234 & 0.231 \\
\hline
\end{tabular}

financial and economic criteria. The public acceptance is more significant than the other three social criteria and human health is more important than job creation. In the practical criteria, the maintainability is considered to be the most important than the other two criterions.

The alternatives consist of five policy options: improvement of industrial energy efficiency (Alt1); switching to natural gas (Alt2); combined heat and power in designate factories (Alt3); efficient electricity end-use devices (Alt4; and process integration (Alt5). Alternatives were evaluated based on their subjectively estimated contribution to each criterion. The results of evaluation are presented in Table 4. Five policy options are prioritized with respect to the overall score of each alternative, which is computed by multiplication of its scores for criteria with the corresponding weights obtained by AHP. Energy efficiency improvement policy was evaluated to be the most competitive for industrial energy policy with a score of 0.355 , followed by efficient electricity end-use policy and process integration policy with a slightly lower score. Policy for CHP in designate factories was form the fourth priority. Switching to natural gas policy was ranked the lowest.

\section{Conclusions}

This paper applied energy modeling and multi-criteria assessment to develop, and evaluate a set of policy options which explore a range of technical, managerial and behavioral options for Thailand's industrial sector. The overall research question is whether there are energy policies to make the development in Thailand's industrial sector more sustainable economically, socially and environmentally. A contribution of this paper lies in combining energy model and MCDM approach to identify industrial policy options that can promote and prepare pathway towards low-carbon economy.

Results from the modeling study shows that under the BAU scenario the industrial energy demand would be 75,945 ktoe by 2030 and the $\mathrm{CO}_{2}$ emissions are estimated to be $198 \mathrm{MtCO}_{2}$ in the same year. Among energy-related $\mathrm{CO}_{2}$ emissions from industrial sector it is found that electricity and coal are the main sources of emissions. In the alternate scenario, the energy efficiency improvement and process integration have great potential to reduce energy demand and $\mathrm{CO}_{2}$ emissions as well as improve the local air pollutants as co-benefits relative to the BAU scenario. These policies have the potential of energy-savings of 30,336 ktoe and $79.02 \mathrm{MtCO}_{2}$ emission reductions in 2030. These amounts of energy-saving are important for Thailand, since the country depends upon imported fuels. Nevertheless, if all industrial policy options are simultaneously implemented, the highest potential of energy-savings in 2030 is expected to be 37,845 ktoe. There would be a reduction of $117.94 \mathrm{MtCO}_{2}$ by 2030.

The prioritization of five industrial policy options was carried out by AHP and Web-HIPRE. The study developed a three-level hierarchy structure, with five main criteria, and evaluated the importance and the competitiveness of each policy option. The evaluation of industrial energy policies can be concluded that the energy efficiency improvement and is ranked highly in all dimensions of sustainable development with a score of 0.355 . The findings suggest that efficient electricity enduse devices and process integration have priority for policy interventions. Results of modeling and evaluating 
policies provide useful, policy-relevant information, and can be used as a basis for priority policy planning in the industrial sector.

\section{Acknowledgements}

This work was made possible by the financial support from the Science and Technology Research Institute, King Mongkut's University of Technology North Bangkok (KMUTNB), Thailand. This work was also benefited from the discussions at Department of Industrial Engineering, Faculty of Engineering, KMUTNB. The authors also gratefully acknowledge the Stockholm Environmental Institute-Boston Center for supporting LEAP model, and the System Analysis Lab., Helsinki University of Technology, Finland for the Web-HIPRE, webbased decision analysis software.

\section{REFERENCES}

[1] S. C. Bhattacharyya and A. Ussanarassamee, "Decomposition of Energy and $\mathrm{CO}_{2}$ Intensities of Thai Industry between 1981 and 2000,” Energy Economics, Vol. 26, No. 5, 2004, pp. 765-781. doi:10.1016/j.eneco.2004.04.035

[2] Department of Alternative Energy and Efficiency (DEDE), “Thailand Energy Situation 2005," Ministry of Energy, Bangkok, 2005.

[3] Stockholm Environment Institute (SEI), "LEAP, LongRange Energy Alternative Planning System.” http://forum.seib.org/leap

[4] A. Phdungsilp, "Integrated Energy and Carbon Modeling with a Decision Support System: Policy Scenarios for Low-Carbon City Development in Bangkok," Energy Policy, Vol. 38, No. 9, 2010, pp. 4808-4817. doi:10.1016/j.enpol.2009.10.026

[5] R. P. Hämäläinen and H. Lauri, "HIPRE 3+ User's Guide,” System Analysis Laboratory, Helsinki University of Technology.

http://www.sal.hut.fi/Downloadables/ hpdemo.html

[6] R. L. Keeney and H. Raiffa, "Decisions with Multiple Objectives: Preference and Value Tradeoffs,” John Wiley \& Sons Inc, New York, 1976.

[7] T. L. Saaty, “The Analytic Hierarchy Process,” McGraw-Hill Inc, New York, 1980.

[8] T. L. Saaty, "Highlights and Critical Points in the Theory and Application of the Analytic Hierarchy Process," European Journal of Operational Research, Vol. 74, No. 3, 1994, pp. 426-447. doi:10.1016/0377-2217(94)90222-4

[9] A. Salo and R. P. Hämäläinen, “On the Measurement of
Preferences in the Analytic Hierarchy Process,” Journal of Multi-Criteria Decision Analysis, Vol. 6, 1997, pp. 309-343.

doi:10.1002/(SICI)1099-1360(199711)6:6<309::AID-MC DA163>3.0.CO;2-2

[10] Department of Alternative Energy Development and Efficiency (DEDE), “Energy Potentials,” Ministry of Energy, Bangkok, 2006.

[11] Department of Industrial Works (DIW), "Thailand Factory Databases,” 2008. http://www.diw.go.th/diw

[12] Department of Industries and Mines (DPIM), “Thailand Mine Databases,” 2008. http://www.dpim.go.th

[13] National Economic and Social Development Board (NESDB), "National Income of Thailand, 1980-2001 ed.," Bangkok, 2003.

[14] National Institute of Development Administration (NIDA), “Thailand Long-Term Load Forecasts,” Bangkok, 2006. http://www.eppo.go.th/load/nida/eng/contents. html

[15] S. Tanatvanit, B. Limmeechokchai and S. Chungpaibulpatana, "Sustainable Energy Development Strategies: Implications of Energy Demand Management and Renewable Energy in Thailand," Renewable and Sustainable Energy Reviews, Vol. 7, No. 5, 2003, pp. 367-395. doi:10.1016/S1364-0321(03)00066-2

[16] B. Sajjakulnukit and P. Verapong, "Sustainable Biomass Production for Energy in Thailand," Biomass and Bioenergy, Vol. 25, No. 5, 2003, pp. 557-570. doi:10.1016/S0961-9534(03)00091-6

[17] R. M. Shrestha, S. Malla and M. H. Liyanage, "ScenarioBased Analyses of Energy System Development and its environmental Implications in Thailand," Energy Policy, Vol. 35, No. 6, 2007, pp. 3179-3193. doi:10.1016/j.enpol.2006.11.007

[18] M. Kainuma, Y. Matsuoka and T. Morita, "Climate Policy Assessment: Asia-Pacific Integrated Modeling,” Springer, Tokyo, 2003.

[19] J. Santisirisomboon, "Modeling of Energy and Environmental Systems in Thailand for Energy Conservation and Emission Mitigation,” Ph.D. Thesis, Thammasat University, Bangkok, 2001.

[20] R. M. Shrestha, P. Khummongkol, W. K. Biswas, G. R. Timilsina and S. Sinbanchongjit, " $\mathrm{CO}_{2}$ Mitigation Potential of Efficient Demand-Side Technologies: The Case of Thailand,” Energy Sources, Vol. 20, No. 4-5, 1998, pp. 301-316. doi:10.1080/00908319808970063

[21] National Energy Policy Office (NEPO), "Energy Efficiency Standards Regime Study,” Environmental Resource Management (ERM), Bangkok, 1999. 
172 Energy and Carbon Modeling with Multi-Criteria Decision-Making towards Sustainable Industrial Sector Development in Thailand

Table A-1. Energy demand of industrial sub-sector in BAU case (ktoe).

\begin{tabular}{|c|c|c|c|c|c|c|c|c|c|c|c|c|}
\hline & \multicolumn{4}{|c|}{ Coal } & \multicolumn{4}{|c|}{ Petroleum Product } & \multicolumn{4}{|c|}{ Natural Gas } \\
\hline & 2005 & 2010 & 2020 & 2030 & 2005 & 2010 & 2020 & 2030 & 2005 & 2010 & 2020 & 2030 \\
\hline Food and Beverage & 0.1 & 0.1 & 0.2 & 0.3 & 162 & 202 & 345 & 589 & 7 & 8 & 14 & 24 \\
\hline Wood and Furniture & - & - & - & - & 4 & 6 & 9 & 16 & - & - & - & - \\
\hline Paper & 141 & 176 & 300 & 513 & 73 & 91 & 156 & 267 & - & - & - & - \\
\hline Chemical & 796 & 992 & 1695 & 2895 & 75 & 93 & 159 & 271 & 1127 & 1404 & 2398 & 4097 \\
\hline Non-metallic & 5818 & 7251 & 12,386 & 21,156 & 18 & 22 & 38 & 65 & 425 & 529 & 904 & 1544 \\
\hline Basic Metal & 41 & 51 & 87 & 148 & 60 & 75 & 128 & 218 & - & - & - & - \\
\hline Fabricated Metal & - & - & - & - & 9 & 11 & 19 & 33 & 141 & 176 & 301 & 514 \\
\hline Others & 512 & 638 & 1090 & 1861 & 553 & 689 & 1177 & 2010 & 7 & 9 & 15 & 26 \\
\hline \multirow[t]{2}{*}{ Total } & 7308 & 9107 & 15,557 & 26,573 & 1020 & 1271 & 2171 & 3708 & 1711 & 2132 & 3642 & 6222 \\
\hline & \multicolumn{4}{|c|}{ Renewable ${ }^{*}$} & \multicolumn{4}{|c|}{ Electricity } & \multicolumn{4}{|c|}{ Total } \\
\hline Food and Beverage & 5331 & 6644 & 11,349 & 19,385 & 669 & 833 & 1423 & 2431 & 6169 & 7687 & 13,131 & 22,430 \\
\hline Textile & - & - & - & - & 979 & 1220 & 2084 & 3559 & 1049 & 1307 & 2233 & 3815 \\
\hline Wood and Furniture & 2 & 3 & 5 & 8 & 130 & 162 & 277 & 472 & 137 & 170 & 291 & 496 \\
\hline Paper & - & - & - & - & 174 & 217 & 370 & 632 & 388 & 484 & 826 & 1412 \\
\hline Chemical & 32 & 40 & 68 & 116 & 846 & 1055 & 1802 & 3078 & 2876 & 3584 & 6121 & 10,456 \\
\hline Non-metallic & 247 & 308 & 526 & 899 & 492 & 614 & 1048 & 1790 & 7001 & 8724 & 14,902 & 25,455 \\
\hline Basic Metal & - & - & - & - & 542 & 675 & 1153 & 1970 & 643 & 801 & 1368 & 2,337 \\
\hline Fabricated Metal & - & - & - & - & 1399 & 1743 & 2977 & 5085 & 1549 & 1930 & 3297 & 5632 \\
\hline Others & - & - & - & - & 4 & 5 & 9 & 15 & 1076 & 1341 & 2291 & 3913 \\
\hline Total & 5613 & 6994 & 11,947 & 20,408 & 5235 & 6523 & 11,143 & 19,034 & 20,887 & 26,028 & 44,460 & 75,945 \\
\hline
\end{tabular}

* Renewable energy is including bagasse, biomass and wood. 